\title{
LA DEMOGRAFÍA EN EL CONTEXTO DE VALENCIA. SIGLO XV
}

\author{
Álvaro Santamaría
}

\section{EL TEMA VALENCIA. SIGLO XV}

El siglo XV valenciano es tema abierto, tema historiográficamente pendiente, sembrado de áreas superficialmente tratadas o rutinariamente conocidas. No obstante, dicho siglo ha encontrado en la historiografía valenciana atención especial y, pienso, tratamiento privilegiado objetivable en valiosas aportaciones'.

La atención singular que le ha prestado la historiografía viene a ser el reflejo inducido de la fascinación que Valencia, en el siglo XV, despertaba, tanto entre naturales como entre extraños al Reino, que aparentaban inmersos, pese a soterradas tensiones banderizas y a la preocupación por el incremento de la deuda pública, en tiempos de relativa plenitud, entre afanes y esperanzas.

1 A destacar, sobre todo, la esencial tesis doctoral de ERNEsto Belenguer, Valencia en la crisi del segle xv, Barcelona, Editorial 62, 1975. Ofrece una ponderada panorámica global sobre el siglo Xv y es exhaustiva en algunos aspectos para la época de Fernando el Católico. LEOPOLDO PLBS ha elaborado, entre otros estudios de interés: Apuntes para la historia económico-social de Valencia durante el siglo xv, Valencia, Ayuntamiento, 1969; Estudio documental sobre el bayle general de Valencia, su autoridad y jurisdicción. Vafencia, Institución Alfonso el Magnánimo, 1970; y La población de Valencia a través de los Llibres de avehinaments. 1400-1449, Valencia, Ayuntamiento. 1978.

Sobre el siglo Xv, ÁlVAro SAmTAMARí, Aportación al estudio de la economía de Valencia durante el siglo XV. Valencia, Institución Alfonso el Magnínimo, 1966. FinA QUERoL, La vida valenciana en el siglo xv, Valencia, Institución Alfonso el Magnánimo, 1963.

Muy notable es la tesis doctoral de Francisco Roca, El justicia de Valencia, Valencia, Ayuntamiento, 1970. También, La inmigración a la Valencia medieval, Castellón, Sociedad castellonense de cultura, 1976.

Es asimismo importante la aportación de Francisco Sevillano, Valencia urbana medieval a través del oficio de mustaçaf. Valencia, Institución Alfonso el Magnánimo, 1957: «Las empresas nacionales de los Reyes Católicos y la aportación de la ciudad de Valencian, en Hispania, p. 57, 1954, 512-623: Préstamos de la ciudad de Valencia a los reyes Alfonso V y Juan II, 1426-1472, Valencia, Institución Alfonso el Magnánimo, 1951. 
Obran sobre la sensación de progreso conocidos testimonios. Y no me refiero a la literatura oficialista, laudatoria, como la del humanista Lucio Marineo Siculo, autor de la primera Crónica Daragon, impresa primorosamente en Valencia, en alarde editorial. En la casa y oficina -precisa textualmente el pie editorial-dicha Lo Moli de la Rovella por industria del experto y en este arte asaz docto Juan Jofre señor y maestro de la Casa sobredicha, en edición que técnicamente puede ser índice del brillante nivel cultural de la Valencia renacentista ${ }^{2}$. Lucio Marineo Siculo, que callejeó por Valencia, la considera inter primas totius Hispaniae urbes enumeranda est ${ }^{3}$.

Tampoco me refiero al lenguaje diplomático, al lenguaje cortés y protocolario de huéspedes agradecidos, abrumados por el comportamiento de la ciudad anfitriona que procura, porque lo lleva en su talante colectivo, desde la dignidad y desde la generosidad, agasajándoles por ser huéspedes de honor del rey de Valencia; deseosa la ciudad de dejar alto su prestigio comunitario, los fueros capitalinos y también la honra de su rey.

Lo relata el capellán de Alfonso el Magnánimo cuando al mentar comentarios del infante don Pedro de Portugal y de personas de su cortejo, huéspedes de Valencia en 1438, refiere: Digueren que verdaderament creien que no havia ciutat en tot lo mon como Valencia, car ells havien vist molt y tot lo restant no ere res ${ }^{4}$.

Obran además testimonios más objetivos, espontáneos, que poco tienen que ver con el lenguaje cortés o agradecido como, por ejemplo, el joven mercader florentino que en estancia de tránsito arriba a Valencia en 1440 y le escribe a su madre: Este mercado es más variado y barato que el de Barcelona. Aqui, madre, abundan las hortalizas y las frutas y con un solo dinero dan más naranjas de las que uno puede llevar.

El joven mercader era Amadeo Strozzi, de la razón social Strozzi y compañía, que a la sazón disponía de un capital escriturado — su capital circulante era mucho mayor- de 325.000 sueldos moneda de Valencia; y poseía la Sociedad Strozzi - a modo de multinacional del siglo XV-: agencias abiertas en Barcelona, de donde venía Amadeo; en Brujas, a

${ }^{2}$ La Crónica se publicó en 1524. Ediciones El Albir ha publicado una edición facsímil (Ediciones El Albir, Barcelona 1974).

${ }^{3}$ Marineo Siculo coincide en ello con Nicolás von Poplaw, que antes, en 1484, había manifestado: Valencia está mejor y más ordenada que cualquier otra ciudad del rey (cit. por Francisco Sevill.ano, *Las empresas nacionales de los Reyes Católieos*, p. 531).

${ }^{4}$ Dietari del capella d'Anfós el Magnanim. Introducción, notas y transcripción por JosE SANCHIS SIVERA, Edición Acción Bibliográfica Valenciana, 1932, p. 132. El Dietari contiene cantidad de testimonios acerca de las atenciones con que la ciudad de Valencía solía atender a los huéspedes ilustres. 
donde se encaminaba Amadeo a bordo de galeras fletadas por la Sociedad; en Palermo; en Nápoles; $y$, por supuesto, en Valencia.

No se trata sólo del testimonio válido de un mercader, pues en la misma línea testimonial está el térico de la economía Benedeto Cotrugli, que, en su tratado Della Mercatura e del mercante perfeto, informa: El reino de Valencia, por su propia naturaleza, es abundantisimo, y no lo digo de ahora sino según he comprendido del pasado ${ }^{6}$.

La Administración, por su parte, opinaba que Valencia se encontraba en mejor situación para aportar recursos a las empresas de la Corona que Barcelona o que Mallorca. Por ello, cuando en 1494 los jurados de Valencia se manifestaban remisos a armar galeras anticorsarios, Fernando el Católico replicó: Valencia pot pagar e fer totes les galeres ab molt maior facultad $[$...] que no Barcelona ni Mallorques?

\section{La expresión: Siglo XV - Siglo de Oro}

Los testimonios historiográficos, que tienen su peso ${ }^{8}$, son coherentes con lo que en ocasiones manifiestan las fuentes documentales, por lo que no es sorprendente que la historiografía valenciana a partir de sus primeros balbuceos, desde Pere Antoni Beuter, incardinado en la valencianidad, tienda a contemplar el siglo XV como época cenital del Reino de Valencia?'

5 Cit. por MARIO DEL TREPro, Els mercaders catalans i l'expansió de la Corona Catalano-Aragonesa al segle XV (Título original, I mercanti catalani e l'espansione della Corona d'Aragona nel secolo Xv), Barcelona, Curial, 1976, p. 492-493.

${ }^{6}$ Cit. por DEL Treppo, Els Mercaders, nota 4, p. 268-269.

${ }^{7}$ Cit. pot SEVLLLANO, Empresas nacionales, p. 533-534.

8 . [Valencia] regalo universal y continuo de toda España, cuya vega y territorio es no solamente de los más ricos y apacibles que hay en todo reino habitado de la tierra, como casi todo el reino cuya cabeza es la ciudad» (Zuruta, Anales de Aragón, Zaragoza, Institución Fernando el Católico, 1967, tomo I, p. 530). «De lo que diferentes autores estranjeros sienten de la ciudad y reino de Valencia», Gaspar Escolano, Década primera de la historia de Valencia, Valencia 1610, edic. facsímil, Departamento de Historia Moderna, Universidad de Valencia, 1972, columnas 1115-1136. *Tois els viatgers esurangers comenten escandalizats el fast urbá $i$ les ostentoses vestimentes de les dones valencianes al voltant del 1500. (SANCHis GuARNER, «Aspecte urbá valencià al segle XVis, VIII Congreso HCA, Valencia 1967, tomo II, vol. I, p. 98).

9 «La cíudad de Valencia pasó de los tiempos medios a los modernos sobre una ola de rigueza [...] que hacian de Valencia digna rival de las ciudades renacentistas italianas (SEVILLANo, Empresas nacionales, 512). «El auge económico valenciano se produce fundamentalmente en el siglo XV y no sólo por causas internas sino por factores externos entre los cuales quizás el más interesante sea el conocer la intervención que tuvieron los extranjeros. preferentemente italianos» (PILES, «Actividad y problemas comerciales de Valencia en el cuatrocientosw, V Congreso de HCA, Cerdeña 1957, Ministerios de Asuntos Exteriores, Madrid 1959, p. 411). 
Importa aclarar, sin embargo, que no es precisamente la historiografía regnícola - la romántica o la renovada- la que acuña en relación a Valencia las expresiones Edad de Oro o Siglo de Oro. La expresión Edad de Oro es de Earl Hamilton, que en 1936 escribe: En el siglo XV Valencia no sólo disfruta de su período de mayor prosperidad económica, sino que vive su Edad de Oro en la literatura, la erudición y las bellas artes ${ }^{10}$.

Expresión Siglo de Oro que, desde una metodología asentada en el materialismo dialéctico, asume en 1957 Pierre Vilar cuando dice que en Valencia el Siglo de Oro es el siglo XV y que Valencia en la época de los Reyes Católicos es la ciudad española más penetrada en el ambiente renacentista ${ }^{11}$.

«En los comienzos del siglo Xv Valencia era ya una ciudad importante [...] porque su florecimiento municipal la llevaba paulatinamente bacia otro florecimiento, el económico, que le iba a permitir en la segunda mitad del siglo xv atraer hacia ella el centro comercial y económico de la Corona de Aragón, perdiđo por Barcelona a raíz de la guerra de Cataluñas (AMPARo Curves, «Abastecimiento de la ciudad de Valencia durante la Edad Medias, Saitabi. 12, 1962, p. 142).

«A través del movimiento comercial que a fines del siglo XIV mantiene Vafencia con puertos de Italia y Berbería cabe advertir un desarrollo del reino valenciano cada vez más brillante [...] Es muy posible que ya en la segunda mitad del siglo xIv tenga en fermento los gérmenes de su esplendor del Xv y, por tanto, la crisis catalana de 1462 no habría influido de la manera tan decisiva que tradicionalmente se aceptas (RAFAEL ARroyo, $*$ Comercio de exportación de Valencia con Italia y Berberia a fines del siglo XIVn, VIII Congreso HCA, Valencia 1967, tomo II vol. III, 1970, p. 272).

*Nombrosos historiadors han posat de relleu com l'opulenta burguesia valenciana fou el suport financier de diverses empreses dels reis Catölies i que durant el seu regnat Valencia fou la capital financiera de la monarquia, segons ha formulat Sevillano Colom» (MaNUFı. SANCHIs GUARNER, «Aspecte urbà de Valencia al segle XVIs, VIII Congreso HCA, Valencia 1967, tomo III, vol. I, 1973, p. 97 ).

«Valencia, gracias al extraordinario auge económico y comercial, contribuyó en gran manera a aliviar los apuros financieros en que se debatieron los monarcas de la Corona de Aragón durante el siglo XV (PEDRO LOPEZ ELUM, «El censal como remedio al préstamo que Valencia ofreció a Alfonso V en 1442n. Primer Congreso del País Valenciano, Valencia 1971. Universidad de Valencia, vol. II, 1980, p. 709).

${ }^{10}$ Earl I. Hamiton, Money, prices and wages in Valencia, Aragon and Navarra. 1351-1500, Harward Economic Studies, Cambrigde-Massachussets 1936, 63.

${ }^{11}$ La iesis de Vilar es que aunque Valeneia influye decisivamente en la coyuntura de Caspe, entonces, en 1412, no estaba todavía en situación próspera, pues su «Siglo de Orow es el siglo XV. cuando alcanza preponderancia apoyada en su riqueza agraria y en sus producciones artesanas de lujo (VILAR, «Le déclin catalan du bas Moyen Age. Hypothèse sur sa chronologiew, en Estudias de Historia Modema VI, Facultad de Filosofia y Letras de Barcelona, cita 23-24.

Es correcto el criterio de Vilar de que Valencia al comenzar el XV no había alcanzado tanto progreso. A la sazón, como documentan las fuentes de la época y en especial los Manual's de Consells del AMV, la situación era de inestabilidad, no sólo a consecuencia de las luchas de bandería, que obligaron a Martín el Humano a secuestrar la administración municipal en 1406 y a nombrar a título de virrey $-\mathrm{cl}$ primero documentado en Valencia-con plenos poderes a don Ferrán López de Luna, sino de resultas del crecimiento de la deuda pública desde el último cuarto del siglo XIv, lo que determinó instituir - ya a fines del xIV - el 
Los valencianos del siglo XV, ¿qué pensaban de Valencia? Pese a sus banderías impenitentes se mostraban afanosos entre otras cosas en remodelar la estructura viaria de su ciudad, que conservaba - no obstante los cambios producidos desde el último cuarto del siglo XIV- la impronta musulmana, para mudarla, por lo menos en las áreas urbanas más céntricas, en moderna y vistosa, para adecuarla a las exigencias crecientes del tráfico, alineando y ensanchando los ejes viarios de enlace, esponjando plazas y levantando edificios singulares; singulares por su empaque y monumentalidad, pensados para impresionar al espectador propio y al foráneo.

Cuando en 1418 se proyecta la nueva Casa de la Comunidad, un Ayuntamiento nuevo, se aspira a un edificio símbolo de la ciudad, una especie, diríamos en nuestro lenguaje, de logotipo urbano de Valencia. EI Consell acuerda lo siguiente: Fer una insigna Casa axi bella e costosa com fer se puga [...] tal com conve a tan egregia e insigne e notable ciutat como aquesta.

En 1480 la Lonja de mercaderes estaba vieja y obsoleta. Era una estructura de comienzos del siglo XIV situada a la vera de la alcaicería, ya documentada en 1314. Es cierto que, según mis notas, se practicaron obras para ampliarla entre 1344 y 1346, en 1377 y, por lo menos, en 1439; pero a pesar de los arreglos la Lonja no era lo que tenía que ser, por lo que el 9 de diciembre de 1480 el Consell tomó el acuerdo de levantar la Lonja nueva.

El acuerdo del Consell precisa que la Lonja nueva tenía que ser molt bella e magnifica e sumptuosa, que sia honor e ornament de aquesta insigne ciutat. Obraba el propósito de realizar una inversión que a la par que dignificara la ciudad resultara inversión rentable pues, con buen sentido, se pensaba que la rentabilidad no sólo se contabiliza en dineros.

Se pretendía crear un marco de encuentro para los mercaderes, a la vez estimulante y relajante, per que los mercaders - dice textualmente el acta- tinguen afectio a exercitarse en lart mercantivol, e fer naus, de que resultara a Valencia grandissim benefici ${ }^{12}$.

racional con el propósito de racionalizar la deuda. Valencia vive, sobre todo entre 1399 y 1411 , en ambiente como de pesadilla. En el Consell General se dedican sesiones monográficas a la problemática de las banderías, dels bandejats, de los puestos fuera de ley por sus desafueros.

Frente a lo que la historiografía valenciana suele a veces asumir, los Trastámara, apreciada la situación en su conjunto, recibieron un reino de Valencia en trance de caos, similar al existente entonces en el reino de Mallorca, en el reino de Aragón y, en parte, en el principado de Cataluña.

${ }^{12}$ SANTAMAR1A, Aporiación al estudio de la economía de Valencia, p. 45. 
A partir de los años sesenta se detecta una corriente historiográfica creciente de intencionalidad desmitificadora, que reivindica la aplicación de una metodología histórica más renovada y argumenta que, cual prueba el testimonio del Siglo de Oro español, el auge cultural no es necesariamente signo ni comporta la plenitud económica.

Se arguye que, al ejemplo de Italia, donde las inversiones suntuarias del siglo XVI acaso propiciaron la depresión del XVII, puede pensarse que las inversiones consuntivas realizadas pro monumentalidad de Valencia en el siglo XV incidieron negativamente en la posteridad inmediata, al punto que en los esplendores del XV estaban larvadas las precariedades del XVI.

Comparto el requerimiento de objetivar el pasado al amparo de una metodología adecuada y rigurosa, pero ni considero extrapolable la experiencia del Siglo de Oro hispano al siglo XV valenciano, dado que obran abismales diferencias entre ambos siglos y sus respectivas circunstancias de mentalidades, tiempo y lugar. Tampoco entiendo que el modelo italiano. que de momento no es evidencia verificada sino mera conjetura, sea extrapolable al siglo XV valenciano.

Es difícil asumir, no obstante el crecimiento de la deuda pública - fenómeno, por lo que consta, generalizado, objetivado a escala occidental en casi todos los países - que su expansión en Valencia, aunque evidente. acarreará un legado de deudas de suficiente entidad y volumen como para hipotecar el futuro.

Es cierto que la deuda crece (de un índice 100 en 1400 se pasa a 206 en 1516), pero la tasa media anual de crecimiento (media anual de 0,41), contemplada en el contexto del desarrollo económico valenciano, aunque preocupaba a la Administración y a la realeza, no era de nivel alarmante; y al margen de ello, pudiera considerarse sociologicamente conveniente por la incidencia que el cobro de las pensiones de la deuda - como se razonaba en el último cuarto del siglo XV- en la promoción de la demanda de servicios y productos, en beneficio de la menestralía ${ }^{13}$.

Por otra parte, en cualquier tiempo, tan esencial como el crecimiento de la deuda es la capacidad de cualquier ente para endeudarse y para tener y generar crédito sin disparar la inflación de los precios. A fines de la época de Fernando el Católico, a pesar del impacto de la quiebra de la banca de Baltasar Fores que afectó a la municipalidad, los presupuestos municipales

13 Entre 1400 y 1500 la deuda se incrementa de 18.000 a 40.000 libras con un aumento de 220 libras anuales; lucgo se dispara al pasar entre 1500 y 1516 de 40.000 a 58.000 libras (BELENGUER, Valencia en la crisi del segie $x \mathrm{v}$, p. 45).

En Barcelona la deuda municipal se incrementa entre 1369 y 1396 de 169.000 libras a 386.963 libras con un aumento de 217.000 libras, que determina un crecimiento medio anual de 8.037 libras (VIL.AR, «Déclin catalan॰, p. 32-33). 
se cierran con superávit. Y la Administración, con buen criterio, mantiene - al tiempo que emite Deuda- la política de otorgar créditos a la Corona (un total de 8.434.250 sueldos entre 1484 y 1515).

Lo cierto es que el caso - el progreso- de Valencia resulta, a todas luces, contrastante con las circunstancias que imperaban en el reino de Mallorca, en virtual situación de suspensión endémica de pagos desde 1405; en Barcelona, seriamente acosada por apuros financieros; y en Zaragoza, donde la situación tampoco era boyante ${ }^{\text {. }}$.

No comparto, en relación al siglo XV valenciano, la querencia manifiesta o insinuada a desmitificar lo que no está mitificado aunque en algunos aspectos acaso esté enfatizado. $Y$, sin mengua de profundizar, sin telarañas en la mente ni proclividades sucursalistas, en la investigación y en análisis paralelos — necesidad más que evidente-, entiendo que obran suficientes evidencias como para considerar que la estabilidad socioeconómica y relativa prosperidad, de luces y sombras, tensa y a veces crispada del siglo XV valenciano, no procede contemplarla como historia ficción o mito historiográfico sino analizarla desde la racionalidad $\sin$ rutinarias banalidades ni encubiertas reticencias.

\section{EL INDICADOR DEMOGRÁFICO}

\section{Los testimonios demográficos coetáneos}

Los testimonios coetáneos sobre el desarrollo demográfico de la Valencia del siglo XV suelen ser optimistas. Portavoces calificados de la comuni-

14 Sevillano, Empresas nacionales, 590. La ciutat - se afirma en 1482 en el Consell de Trenta - pren no solament gran deformitat sino gran dan, car ja manca activitat económica, per esser carregts de censos - las viviendas - e cascun jorn enderroquen cases (JAIME Vicfns Vives, Ferran II i la ciutat de Barcelona, Barcelona, Universitat de Catalunya, tomo I, p. 244).

«Aragón pasó a ser considerado por buena parte de los negociantes catalanes como una colonia más de la que extraer materias primas a buen precio, colocar excedentes de industria y distribuir manufacturas llegadas de los viajes de Orienten (ÁNGEL SESMA, Transformación social y revolución comercial en Aragón durante la baja Edad Media. Madrid, Fundación J. March, 1982, 50), Para la deuda aragonesa véase ÁnGez. SESM, La Generalidad del reino de Aragón. Su organización en el siglo Xv, en AHDE, 46, 1967, p. 393-467.

Para la situación en Mallorea, véase Ál varo SANTAMARí, "El reino de Mallorea en la primera mitad del siglo XVm, IV Congreso HCA, Palma de Mallorca 1954, p. 40-46, 49-74, 120-149; «Pragmática de Granada, una década de la historia de Mallorca, 1495-1504\%, Boletín de la Cámara de Comercio y Navegación de Palma de Mallorca, 1971, p. 6-74; \&La Deuda Pública en la Parte Foránea de Mallorca al finalizar el siglo XVn, Anuario de Estudios Medievales, 8, 1972-1973, p. 257-304; eL a gestión fiscal y la coyuntura económica en Mallorca en torno al año 1510 s en Mayurqa, Palma de Mallorca, 14, 1975, p. 22-61. 
dad valenciana urbana se muestran unívocos en la afirmación de que su ciudad es ciudad populosa, ciudad importante. Por ejemplo, en las Contes de 1342 los estamentos representativos le dicen al Rey que la situación no era ya com en lo temps passat quan el regne de Valencia no era tan poblat como ara es ${ }^{15}$.

En 1417 los jurados de Valencia, al tiempo que protestan por la ruptura de las relaciones con Génova, por considerarla atentatoria a los intereses de Valencia, le recuerdan al rey que viny, en Valencia, se fan tanies o mes mercaderies que en alguna altra ciutat de vostra senyoría ${ }^{16}$.

Después, en otra carta, le notifican la urgencia para acelerar los arbitrios para avituallar Valencia, per sa grandea - razonan-que per gracia de Deu hi es e per la multiplicació de gran propulació ${ }^{17}$. Más tarde, en 1483. le reiteran al Monarca: Aquest regne e aquesta ciutat de Valencia es molt populosa $a^{18}$.

Cuando iba a cerrarse el siglo, concretamente en octubre de 1496, se vuelve a insistir en instrucciones elaboradas como argumentación ante la Cancillería real, en que la ciudad, mitjançant gracia de Deu es ben poblada, y en que el motor de la abundancia de vecinos era la variedad de oportunidades de empleo que, per causa de les despeses, por la demanda de productos y de servicios y por el nivel de consumo, tenían los menestrales, que son - notifican los jurados al Rey-en grandissim nombre e per los quals la ciutat es poblad $a^{19}$.

Al efecto, entre 1463 y 1521 se incorporan como gremios reconocidos y con representación propia (dos consejeros cada uno) al Consell General de Valencia nada menos que veinte corporaciones gremiales: tejedores, tundidores, albañiles, tapineros, panaderos, guanteros, sederos, armeros, corredores, molineros, colcheros-matalaseros, tragineros, cinteros, cordele-

${ }^{15}$ Furs e ordinations fetes per los gloriosos reys de A ragó ais regnicols del regne de Valencia, Valencia, Lamberto Palmart, 1482, edición facsímil. Universidad de Valencia, 1976.

${ }^{16}$ Carta de los jurados de Valencia de 31 de diciembre de 1417 contestando a la del rey de 20 de septiembre de 1417 en que requería la ruptura con Génova alegando que no se avenía a indemnizar los daños ocasionados a comerciantes catalanes por el corsario genovés Pedro Rey (JosE Hinojosa, «Relaciones comerciales entre Valencia e Italia durante el reinado de Alfonso el Magnánimos, en EFMCA, X, 1975, p. 509-510).

17 Amparo Cueves, Abastecimiento de Valencia, p. 142.

18 Instrucciones de 7 de mayo de 1483 de los jurados de Valencia a micer Baltasar Gallach, embajador (pub, por BELENGUER, «El problema cerealista en Valencia durante la época del rey Católico. Repereusiones administrativas, económicas y políticas», Hispania, anexo 5, Madrid 1975, p. 204-208).

${ }^{19}$ La afirmación se contiene en las instrucciones encomendadas el 20 de octubre de 1496 a Eximeno Ros oponiéndose a la propuesta real de rebajar los intereses de la deuda pública a 16.000 por 1.000 (al 6,25 por 100). A juicio de los jurados la reduecíón de las rentas incidiría en una disminución de la demanda de productos y de servicios que perjudicaría a los menestrales (pub, por Bel.enguer, Valencia en la crisi del $s . x V$, p. 332). 
ros, carreteros, cirujanos-practicantes, tintoreros de seda, calzateros, cardereros y caldereros.

En 1494 el 57,35 por 100 de los consejeros del Consell General (78 consejeros del total de 136) lo eran en representación de corporaciones gremiales ( 39 corporaciones con participación en el Consell).

Está claro que en los testimonios, aun en los procedentes de personas que, por las funciones ejecutivas que asumían al más alto nivel de la Administración comunitaria, disponían de información adecuada y fehaciente, cabe la subjetividad susceptible de condicionar su atestación.

Por otra parte, dichos testimonios, al no aportar en general cuantificaciones precisas, sólo son admisibles con alcance indicativo, en el sentido de que - en lo que respecta en los testimonios citados- s6lo revelan una tendencia expansiva dentro del proceso demográfico, lo que, si bien es importante y significativo, no es suficiente.

\section{El espejismo de Valencia como macrourbe}

Importa cuantificar el proceso demográfico. De momento, los datos verificados son escasos - sin que la perspectiva de la investigación sea esperanzadora - y ello no sólo referente a la ciudad de Valencia sino al ámbito del Occidente europeo en el Bajo Medievo.

En 1957 apunté que la asignación de 15.000 vecinos a Valencia - equivalentes a unos 75.000 habitantes-, asumida por la historiografía, se me antojaba demasiado importante, y adelanté la conjetura de que tal guarismo pudiera referirse no a la ciudad intramuros sino a la ciudad y a los pueblos del término de su contribución ${ }^{20}$.

Por entonces, ya obraban datos publicados en 1930 por don Rodrigo de Pertegás sobre la demografía de Valencia intramuros apoyados en una anotación marginal continuada por el notario Gaspar Eximeno en un protocolo notarial del Archivo Municipal de Valencia, que informa: En lo present any - 1489 - se conta en la ciutat de Valencia dins los murs vuit milia vuicents coranta cases $^{21}$.

Agustín Rubio ha revisado recientemente la consideración de la macrourbe valenciana de 15.000 vecinos y, tras una ponderada reflexión analítica sobre el origen de aserto tan generalizado en la historiografía, lo

20 a La última cifra -15.000 fuegos-, si se acepta el coeficiente 1:5 representa unos 75.000 habitantes, demografia, sin duda, muy elevada si se refiere exclusivamente a la ciudad; pero aceptable si - cual debe sugerir- comprende por añadidura el término municipal» (SAntAmaria, A portación al estudio de la economía de Valencia, p. 40). Pienso - aunque no obran datos demográficos sobre el término- que los 15.000 fuegos no son asumibles ni siquiera contando con las villas de la contribución de Valencia-ciudad.

${ }^{21}$ AMV, Protocolos Gaspar Eximeno, 1-9. 
relaciona con Bartolomé Villalba, poeta de Jérica nacido en 1548 y fallecido en el siglo XVII.

Entiende que la historiografía ha interpretado mal el vago cálculo demográfico de Villalba poniéndolo fuera de su contexto cronológico, pues «en el caso de tener algún valor - argumenta - sería aplicable a la Valencia de fines del siglo XVı pero nunca a la de fines del siglo XV».

Pienso que la imagen de macrourbe de 15.000 vecinos, posiblemente, ni siquiera encaja con la Valencia de fines del XV1, flagelada por las secuelas demográficas de la Germanía. Y es evidente que, como afirma Rubio, «cualquier análisis demográfico deberá partir de los 8.840 fuegos o casas contadas en el siglo $\mathrm{XV}_{n}{ }^{22}$.

Gaspar Eximeno, el notario que aporta los datos demográficos sobre Valencia en 1489 dados a conocer por don Rodrigo Pertegás, pertenecía a un linaje de notarios incardinado en la Administración municipal valenciana y, precisamente en 1489, comienza a ejercer como notario-escribano de la Universidad (scribe magnifici Concilii et Domorum juratorum civitatis Valentie), función en la que, al parecer, sucede a Jaime Eximeno, acaso progenitor suyo.

Gaspar Eximeno ejerció su cometido de notario-escribano de la juraría por lo menos hasta $1501^{23}$. El desempeño de su función le facilitó el acceso a datos de primera mano, que pueden aceptarse como fiables, y a noticias de diversa naturaleza que eventualmente consigna, como recordatorio, en notas marginales escritas en sus protocolos ${ }^{24}$.

22 Rubio considera que se registra un «estirón demográficom entre mediado el siglo Xrv y fines del siglo XV y que «el fuerte estirón debió producirse, en efecto, durante el siglo XVw, «Sobre la población de Valencia en el cuatrocientoss, BSCC, 59, 1980, p. 158, 166, 168, 170.

${ }^{23}$ Los protocolos de Jaime Eximeno senior (52 registros) cubren el período de 144-1489. Gaspar Eximeno (18 registros) ejerce como notario-escribano de la universidad conjuntamente con Jaime Eximeno junior, acaso su hermano (3 registros de 1497 a 1501). AMV, Protocolos, 6-7-8-9-10 y s-t-u-y.

24 . Divendres 13 de marc del any 1489 , fonch tan gran foriuna de mas ques perderen moltes fustes e naus entre les altres una carregada de forment e altra de vi.

-Dimecres 18 de marc, romperen la preso molta gent armada, la qual vengueren de ciutat e tragueren tota la gent axi del Urell com de la Casa Fosqua, e dias que moosen Vilaroig ho feu fer.

wDijous a 25 marz any present LXXXVIII, muri micer Miquel Dalmau advocat de la insigna Valencia, advocat fiscal.

od de noembre del any 1489 , la maiestat del rey nostre senyor prenla de mans de infaeis la ciutat de Baca ab les ciutats de Porquna y Berga e de Tavernes e altres castells de la ciutat e regne de Granada.

*A 19 de noembre any 1489 , segui en la present ciutat de Valencia que hunhom apellat Bernardi de Mallorquas que era correger per enuig qui hi falo en Francesch Despi notari, lo dit Bernardi li llança en lo pou per una liura de arsenich en lo pou, perque bevent en aquell es matas, e axí ans que hi begues algu foren descubert e pres. En lo dia dit li tallaren lo puny davant la casa del dit en Despi e aprés lo penjaren en lo Mercats (AMV, Protocolos Gaspar Eximeno, 1-9). 
Los 8.840 vecinos, si se asume el coeficiente convencional $1: 4,5$ - acaso el más ajustado al momento concurrente- comportan una población de unos 40.000 habitantes.

Tal demografía sugiere - si se asumen los cálculos de Burns- un crecimiento a partir de la conquista del orden del 266 por 100; es decir, la ciudad, desde la conquista, había duplicado muy ampliamente su población. Si se parte de la situación demográfica de 1355 , cuando obran datos fiables del morabatín, el crecimiento resultante es del 187 por 100, al pasar de 4.729 vecinos en 1355 a 8.840 vecinos en 1489 .

Al alcanzarse en 1510 la cota de 9.879 vecinos la correlación resultante de la escalada demográfica eleva el índice a 329 por 100 respecto al nivel demográfico de la conquista, y a 208 respecto a la demografía objetivada por el morabatín de 1355 .

¿Qué lectura procede aplicar a dichos índices? Esos índices manifiestan una tasa media anual compensada de crecimiento demográfico de 33 vecinos - no almas - anual. A todas luces es tasa importante, muy considerable y significativa.

Al finalizar el siglo XV la escalada demográfica había convertido a Valencia en la ciudad más populosa de la monarquia de España dado que Sevilla - segundo lugar - contaba en torno a 8.000 vecinos; Barcelona, 5.749 (en 1497); Zaragoza, 3.230 (en 1492); y Palma de Mallorca, 2.950 (en 1489).

Al finalizar el sigio Valencia podía figurar en la clasificación demográfica de las grandes ciudades europeas, por debajo de París, Milán, Venecia, Génova y, en nuestra península, por debajo de Lisboa, a la que se acreditan unos 10.000 vecinos.

Al finalizar el siglo los valencianos tenían conciencia del rango demográfico de Valencia. En 1499, en el preámbulo del Estatuto facultativo del Estudio General se apoya la erección del centro universitario en la conveniencia de que los estudiantes puxen hoyr e aprofitar en la present ciutat la qual - se razona- es mes populosa que ciutat de tota Espanya.

No sólo tenían conciencia del rango de su ciudad sino que manifestaban una valencianidad $\sin$ reticencias, como satisfecha y militante. En totes les parts del mon - se afirma con énfasis y petulancia en el expresado preámbulo- hon ha valencians, aquells son preferits entre tots altres per lurs bons enteniments e disposicions de animo e sperits ${ }^{25}$.

25 BURNS entiende que puede aplicarse a Valencia, en 1239, un promedio parroquial de 250 familias o 1.300 personas (indice 1:5) y se apoya en la nota de VERONNE, «Recherches sur la chiffre de la population musulmane de Valencie en 1238 d'après le Repartiments, BH, p. 51 , 1949 , p. 423-426. 
Cuando la tendencia generalizada era de declive demográfico, Valencia presenta la imagen de una ciudad en desarrollo demográfico. En la monarquía española sólo Sevilla, con un excepcional índice de crecimiento (306 entre 1384 y 1492) superó el estirón demográfico de Valencia, pues la tónica en general no sólo era depresiva sino en algunos casos desoladora.

Lo normal, en los testimonios documentales coetáneos, no es la alusión eventual a la populosidad urbana (aquesta ciutat de Valencia es molt populosa) sino que suele deplorarse la despoblación urbana. La población de Palma de Mallorca, por ejemplo, a fines del siglo XV se había reducido a la mitad de la de 1329, cuando bajo la administración de la dinastía de Mallorca alcanza la Corona de Mallorca el apogeo cultural, económico y demográfico.

La población de Barcelona en 1497 - ya parcialmente recuperada de los efectos de la guerra civil catalana - había disminuido en más de una cuarta parte respecto a la acreditada en 1359, cuando la ciudad, según la información obrante, alcanza su marca demográfica cenital en el Bajo Medievo ${ }^{26}$.

En la Corona de Aragón, a nivel de ciudades punteras de la comunidad, únicamente Zaragoza - aparte de Valencia - escapó al declive demográfico, pues, entre 1369 y 1495 , se constata un alza muy moderada (115 por 100).

\section{Demografia de Valencia-reino}

Gaspar Eximeno no sólo ha consignado la demografia fiable de Valenciaciudad en 1489, sino que da noticia en nota marginal de la demografía de Valencia-reino en el mismo año: 50.000 casas, lo que si se asume el índice 1:4,5 comporta una población aproximada de unas 225.000 almas. ¿En todo el reino? Por supuesto. En la mención de 50.000 vecinos entran todos los del Reino, pagaran o no pagaran la contribución o taixa que motivó - afortunadamente - el recuento demográfico consignado por Eximeno ${ }^{27}$.

BURNS piensa en una Valencia de 15,600 almas (12 parroquias), demografia que, a mi entender, es aceptable para la población de Valencia intramuros, como se desprende del planteamiento de Burns, pero no a los barrios extramuros (El reino de Valencia en el siglo xm. Valencia, del Cenia al Segura, 1982, p. 190, 216).

Cita del preámbulo del Estudio General, Vicenre Borx, Historia de la ciudad y reino de Valencia, Valencia 1845, tercera edic, facsímil, Talleres Artes Gráficas Soler, I, p. 467.

26 Átvaro Santamaria, «Demografía de Mallorca, Morabatín de 1329», Mayurga, 20, 1984, p. 156-22.

20 Importa subrayar la importancia de los datos que aporta Gaspar Eximeno sobre todo considerando que en Valencia-capital, exenta por privilegio otorgado por Pedro el Ceremonioso el 2 de mayo de 1363 en reconocimiento del esfuerzo y de la resistencia de la ciudad ante el tremendo acoso de Pedro el Cruel de Castilla, del pago del morabatín (AHV, Maestre racional, expediente núm. 10.879). 
De los datos aportados se desprende el siguiente reparto de la demografía total de Valencia-reino entre Valencia-capital y las restantes ciudades y villas:

\begin{tabular}{|c|c|c|c|c|c|}
\hline \multicolumn{2}{|c|}{ Valencia-reino } & \multicolumn{2}{|c|}{ Valencia-capita } & \multicolumn{2}{|c|}{ Otros lugares } \\
\hline Casas* & Coeficiente & Casas & Coeficiente & Casas & Coeficiente \\
\hline 50.000 & 100,00 & 8.840 & 17,68 & 41.160 & 82,32 \\
\hline
\end{tabular}

Fuente: AMV, Protocolos Gaspar Eximeno 1-9 (1489). Elaboración propia.

*Total de *casasn entendidas como unidades familiares.

La correlación vecino/capital - vecino/reino era de: 1 es a 5,66; es decir, por cada vecino poblado en la capital había 5,66 vecinos poblados en el término de la capital o en otras ciudades, villas o lugares del Reino. Ello significa que, a pesar del peso sociopolítico de la capital y de la importancia - como veremos- de la corriente inmigratoria, el fenómeno de la concentración de la población en la capital no era demasiado considerable.

El proceso de concentración de pobladores en la capital era de mucha mayor entidad en el Reino de Mallorca, cual puede apreciarse en el cuadro siguiente:

\begin{tabular}{lcllcl}
\hline Reinos & $\begin{array}{l}\text { Vecinos/ } \\
\text { reino }\end{array}$ & $\begin{array}{l}\text { Vecinos/ } \\
\text { capital }\end{array}$ & Coeficiente & $\begin{array}{c}\text { Vecinos/ } \\
\text { foráneos }\end{array}$ & Coeficiente \\
\hline Mallorca & $9.254^{1}$ & 2.949 & 31,87 & 6.305 & $68,13^{3}$ \\
Valencia & $50.000^{2}$ & 8.840 & 17.68 & 41.160 & $82,63^{4}$ \\
\hline
\end{tabular}

Fuente: Reino de Valencia, AMV, Protocolos Gaspar Eximeno 1-9,- Reino de Mallorca, Francisco Sevillano, La demografía del reino de Mallorca a través del impuesto del morabatín (en BSAL, 34, 1974, 268). Elaboración propia.

1 Número de vecinos que en 1489 pagan el morabatín (impuesto septenal de 8 sueldos - un morabatín - pagadero por los vecinos con patrimonio evaluado en más de 10 libras, moneda de Mallorca).

${ }^{2}$ Número de vecinos del reino pagaran o no pagaran la taixa de 1489.

${ }^{3}$ Correlación vecinos/capital - vecinos/foráneos, 1:3,13.

${ }^{4}$ Correlación $1: 5,65$.

La exención ha implicado que no se dispongan de datos sobre el morabatín como factor de evaluación de la población de Valencia y del Grao, lo que ha problematizado el conocimiento del desarrollo de la demografía urbana, en contraste can lo que acaece en Mallorca, donde obran datos globales de los morabatines recaudados septenalmente en 1329, 1343, 1350, 1364, $1421,1427,1433,1444,1451,1459,1466,1475,1482,1489,1503,1510,1517,1524,1531$, $1538,1545,1559,1566,1573$ y septenios sucesivos.

Por otra parte, la taixa cuyos totales consigna Eximeno es especialmente válida al relacionar todos los vecinos, tanto los que la pagaron como los exentos, mientras que el morabalín sólo cnumera a los vecinos con casa y patrimonio (en Mallorea) superior a diez o más libras de Mallorca, por lo que se plantea la compleja cuestión de la incidencia de los exentos en orden al cálculo de la población total (Álvaro SANTamaría, Demografía de Mallorca. La incidencia de los exentos, p. 206-219). 
En el Reino de Mallorca la capital concentraba el 31,87 por 100 de los vecinos/contribuyentes del reino; es decir, casi una tercera parte de la población total insular, y ello pese al notorio declive urbano (entre 1329 y 1489 la demografía urbana baja 9,20 puntos respecto a la rural $)^{28}$; mientras que en Valencia-capital se concentraba sólo el 17,68 por ciento de la población total valenciana, es decir, algo más de una quinta parte.

\section{ESTRUCTURA DE LA FISCALIDAD}

\section{Demografia y estructura fiscal}

Lo más esencial en la información demográfica de Gaspar Eximeno en relación con la demografía del reino de Valencia en 1489 es que agrupa a los vecinos en seis bloques fiscales:

- Vecinos exentos de la taixa.

- Vecinos que pagan 3 sueldos.

- Vecinos que devengan 4 sueldos.

- Vecínos que abonan 10 sueldos.

- Vecinos que satisfacen 20 sueldos.

- Vecinos pechados con 30 sueldos.

Continúo la clasificación fiscal en el siguiente cuadro:

\begin{tabular}{rclcrc}
\hline Casas $^{1}$ & Coeficiente & Tasa fiscal $^{2}$ & Coeficiente & Total taixa3 & Coeficiente \\
\hline 5.000 & 10,00 & 30 & 100,00 & 7.500 & 30,00 \\
10.000 & 20,00 & 20 & 66,66 & 10.000 & 40,00 \\
10.000 & 20,00 & 10 & 33,33 & 5.000 & 20,00 \\
5.000 & 10,00 & 4 & 13,30 & 1.500 & 6,00 \\
10.000 & 20,00 & 3 & 10,00 & 1.000 & 4,00 \\
10.000 & 20,00 & 0 & 0,00 & 0 & 0,00 \\
\hline 50.000 & 100,00 & & & 25.000 & 100,00 \\
\hline
\end{tabular}

Fuente: AMV, Protocolos Gaspar Eximeno 1-9. Elahoración propia.

1 Total de vecinos del reino,

${ }^{2}$ Cantidad devengada en concepto de taixa por el correspondiente bloque o categoría fiseal, en sueldos moneda del reino de Valencia.

${ }^{3}$ Total pagado por la correspondiente categoría fiscal en libras moneda valenciana.

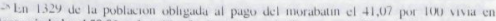
Mallorca-ciudad y el 58,83 en las villas foráneas, lo que indica que en 1489 se habia generado una notable disminución de la población urbana respecto a la existente en 1329 del orden de 9,20 
La clasificación fiscal - materia de ordinario tan incierta, lo que subraya la excepcionalidad de la información de Gaspar Eximeno- es significativa y sugeridora. ¿Quiénes eran los exentos? En la categoría entran tanto los privilegiados exentos por concesión real como el nivel de los más pobres, no de los simplemente pobres, que por no poseer patrimonio o poseer patrimonio testimonial eran exentos.

La incidencia de los exentos, aunque notable ( 20 por 100 de la población total), no parece desmesurada ${ }^{29}$.

\section{Las cinco escalas fiscales}

La información de Gaspar Eximeno viene a constituir como una radiografía de la fiscalidad valenciana de 1489 , de la estructura de la fiscalidad en el reino de Valencia.

El 80 por 100 de la población era pechera, contribuía. ¿Participación alta? Por lo menos tenía un coeficiente participativo muy notable. La taixa, al no obrar proporcionalidad específica en la correlación evaluación patrimonial - aportación contributiva como en las tallas a sueldo y libra (reparto proporcional a sueldo y libra al patrimonio de cada contribuyente obligado al pago de la talla), no era con propiedad impuesto directo.

No obstante, como las escalas o categorías fiscales puede pensarse que se asentaban en las correspondientes estimaciones patrimoniales, es decir, reflejaban una proporcionalidad genérica, la naturaleza de la taixa resulta más afín a la contribución directa que a la contribución indirecta, en la que se contribuye independientemente del patrimonio.

Las escalas expresadas parecen indicativas de una estructura fiscal acaso bastante equilibrada en el sentido de que el bloque de mayores contribuyentes - los grandes patrimonios - constituido por el 10 por 100

puntos; es decir, desde 1329 a 1489 se produce en Mallorca un incremento de 9,20 puntos de la población nural respecto a la población urbana. Pese a ello en 1489 Mallorca-ciudad concentraba el 31,87 por 100 de la población del reino mientras Valencia-ciudad sólo concentraba el 17,68 por 100 de la demografía valeneiana (SAntamarla, Demografía de Mallorca, p. 170, 213).

29 El nivel de exentos es variante de evaluación problemática dada la carencia de datos adecuados para apoyar el cílculo. Para Mallorea, siglos XIV-XYI, Sevillano entiende kque no es exagerado calcular que entre un 25 por 100 y un 33 por 100 de los cabezas de familia no pagaban morabatín, unos por indigencia y otros por franquicia o por privilegios. Por mi parte, al analizar el morabatín de 1329 considero que en dicho año, habida cuenta de las circunstancias concurrentes, el índice de exentos aproximado pudo ser en la población rural del 12 por 100 , en la población urbana del 15 por 100 y en la población judía - más afectada - del 16 por 100 . El índice de exentos es factor muy sensible a la coyuntura económica - que era favorable en Mallorca en 1329 , lo que determina yariantes de uno a otro septenio (SANTA. maría, Demografía de Mallorca, p. 206, 207, 218-219). 
de la población (5.000 vecinos) aporta el 30 por 100 (7.500 libras) del total de la taixa.

El bloque de los contribuyentes medianos - patrimonios medianosconstituido por el 40 por 100 (20.000 vecinos) de la población, paga el 60 por 100 (15.000 libras) del total de la taixa, distinguiéndose en dicho bloque una categoría media alta ( 10.000 vecinos, 20 por 100 de la poblacion, que aportan 10.000 libras, 40 por 100 del total), y otra categoría media baja (10.000 vecinos, 20 por 100 de la población, que aportan 5.000 libras, 20 por 100 de la taixa).

El bloque de contribuyentes pequeños - patrimonios pequeños-, compuesto por 15.000 vecinos ( 30 por 100 de la población), que devengan 2.500 libras (10 por 100 de la taixa,) está integrado por una categoría contributiva de 4 sueldos (5.000 vecinos, 10 por 100 de la población, que aportan 1.500 libras, 6 por 100 de la taixa) y otra categoría más baja de 3 sueldos (10.000 vecinos, 20 por 100 de la población, que aportan 1.000 libras, 4 por 100 de la taixa).

Predominaban lo que, en el lenguaje actual, llamaríamos clases medias (40 por 100 del vecindario que, en este caso, asume el 60 por 100 de la taixa) con una clase media alta ( 20 por 100 del vecindario y 40 por 100 de la taixa) y otra clase media baja ( 20 por 100 del vecindario que devenga el 20 por 100 de la taixa).

Minoría de grandes contribuyentes (10 por 100 del vecindario), aunque constituyen un bloque de cierta entidad que asume el 30 por 100 de la taixa, y una considerable masa de pequeños contribuyentes que representa el 30 por 100 del vecindario y aporta el 10 por 100 del total de la taixa. De esta manera los grandes contribuyentes devengan una cuota diez veces superior ( 30 sueldos) a la que paga la categoría inferior de los pequeños contribuyentes ( 3 sueldos).

Estructuras vertebradas por clases medias

La estructura denota que en el último cuarto del siglo XV las llamadas clases medias burguesas integraban tanto demográficamente ( 40 por 100 del vecindario) como fiscalmente (60 por 100 de la contribución) la columna vertebral de la estructura sociofiscal y económica del reino.

Pienso que el progreso valenciano, sobre todo el progreso urbano, en el $\mathrm{XV}$, en especial en la segunda mitad del XV, se apoya, entre otros factores, en el predominio - en el peso político y socioeconómico- de las masas medias en la estructura social del reino.

La recaudación de los derechos reales sobre consumo de alimentos señalan en los años documentados (1403 a 1443) un alza que, aunque es en 
sí expresiva, resulta más elocuente por la consideración de que es un alza selectiva.

En efecto, mientras el pan, alimento de base, acusa - por lo que se deduce de la subasta del impuesto - un aumento del 115 por 100 similar a la del vino, y la subasta del impuesto de hortalizas - baratas según testimonios de la huerta- aumenta el 113 por 100 , la de los pescados aumenta el 141 por 100 , y el máximo aumento corresponde al producto más caro, la carne, con el índice 258 por $100^{30}$. Ahora bien, en las sociedades occídentales, dentro del sistema alimentario, el aumento de la demanda de carnes constituye el indicador más calificado del nivel de vida.

El caso de Valencia - por los datos obrantes - no sólo es el de una comunidad urbana en crecimiento demográfico, sino el de una sociedad económicamente próspera en la que la demanda de proteínas - definitoria del status de sociedades desarrolladas - tenía cierta importancia y estaba al alza.

\section{INMIGRACIÓN Y POLÍTICA INMIGRATORIA}

\section{La inmigración como factor de estímulo}

¿Cómo se generó en Valencia un crecimiento demográfico relativamente considerable y tan contrastante? Es posible que con una dietética algo nutrida en pescado y también algo en carnes, el crecimiento vegetativo -resultante de la diferencia entre nacimientos y defunciones - fuera positivo. Y hay que pensar que el crecimiento se apoyaba sobre todo en la incidencia de los nacimientos (la media anual de incremento demográfico entre 1355 y 1510 es de 33 vecinos, entendidos no como número de habitantes sino como cabezas de familia).

No obstante, también obró como agente importante del alza demográfica la componente migratoria. Entre 1387 y 1396 está documentada una media anual inmigratoria de 50 inmigrantes, que se reduce en la primera mitad del siglo XV a una media anual de 26 inmigrantes, lo que comporta una diferencia a la baja de unos 24 inmigrantes/año, lo que

${ }^{30} \mathrm{El}$ derecho sobre pan y vino aumentó de 10.000 sueldos (1404) a 13.000 sueldos (1424) para bajar a 11.500 (1426). El derecho sobre bortalizas, de 3.100 sueldos (1405) sube a 3.500 (1426). La gabela de la sal conjuntamente con el pescado de la Albufera y el tereio del pescado de la mar sube de 26.000 sueldos (1422) a 36.000 (1443-1448). La carne pasa de 1.160 sueldos (1403) a 3.000 (1426). Álvaro Santamarla, Aportación al estudio de la economía de Valencia, p. 105. 
disminuye la tasa media anual en un 50 por 100 respecto a la última década del siglo XIV ${ }^{31}$.

Pese a tan importante reducción, la tasa de 26 nuevos inmigrantes/año es considerable, y contribuye a que la demografía de Valencia-ciudad se incrementara a pesar de las agresiones de la peste padecida por lo menos en ocho ocasiones durante el siglo XIV $(1326,1335,1348,1362,1374,1380$, $1383-84$ y 1395) y por lo menos en diez ocasiones durante el siglo XV $(1401,1409-10,1424,1429-30,1438-39,1450,1459-60,1475,1478$ y $1490)$.

\section{Inmigración interior}

En el análisis de la problemática migratoria obran dos componentes de particular interés: la procedencia de la inmigración y la cualificación profesional o laboral de los inmigrantes.

Respecto a la procedencia, el 78,81 por 100 es migración interior de gentes del reino de Valencia que se avecindan en Valencia-capital. Factor positivo porque testimonia la función que la capital ejerce como polo de atracción respecto a casi todas las comarcas del reino sin que se noten diferencias importantes entre comarcas de llanura y comarcas de montaña, ni entre áreas de realengo —áreas de libertad—y áreas señoriales sometidas algunas a jurisdicciones feudales.

No obstante, la corriente migratoria de mayor densidad se genera desde lugares, villas y ciudades reales.

Lo más significativo, como aproximación a la realidad vital, es que casi todos los lugares del reino se integran en el área del movimiento migratorio, de tal manera que puede pensarse - de hecho es la imagen que brindaque la Valencia del siglo XV ejerce como caleidoscopio, como síntesis, de valencianidad $^{32}$.

${ }^{31}$ En las anualidades de $1388-1396$ se registran 498 inmigrantes de los cuales 80 son mercaderes, con una media anual de 29,80 inmigrantes (datos de RAMÓN FERRER, La exportación valenciana en el siglo xIv, Zaragoza, Escuela de Estudios Medievales, 1977).

En los años documentados entre 1400 y 1449 la media anual de eavehinaments» es de 20,06, distribuida de esta manera: 352 entre 1400 y 1409,275 entre 1410 y 1419,274 entre 1420 y 1429,196 entre 1430 y 1439 y 206 entre 1440 y 1449.

La baja es notoria en la primera mitad del siglo Xv: de una media inicial de 27,01 a 15,05 entre 1430 y 1439 y 15,80 entre 1440 y 1449. Datos de LeOpoldo PuLs, La población de Valencia a través de los Llibres de Avehinaments, I400-1449, Valencia, Ayuntamiento, 1978, p. 59 .

32 De comarcas valencianas proceden 163 inmigrantes: 28 de Játiva, 28 de Sagunto, 25 de Cullera, 25 de Gandía, 23 de Alcira, 18 de Liria, 16 de Sueca y de otras localidades.

Los de las comarcas castellonenses proceden de: Segorbe (13), Castellón (12), San Mateo (10), Morella (11) y otras localidades (Llibres de Avehinaments, pub. por PLES). 


\section{Inmigración peninsular}

El coeficiente de inmigrantes peninsulares es notable por su porcentaje (16,58 por 100) y significativo por sus procedencias. Las siguientes:

— 36,56 por 100 de lugares de la Corona de Castilla ( 79 inmigrantes).

- 31,45 por 100 de lugares del reino de Aragón (68 inmigrantes).

- 20,37 por 100 de lugares del principado de Cataluña (44 inmigrantes).

- 5,10 por 100 de lugares del reino de Mallorca (11 inmigrantes).

- 5,10 por 100 de lugares del reino de Portugal (11 inmigrantes).

- 1,39 por 100 de lugares del reino de Navarra ( 3 inmigrantes).

Todos los reinos peninsulares figuran en el movimiento inmigratorio y se integran en porcentajes significativos aunque no sorprendentes.

No es sorprendente el porcentaje acreditado a gentes procedentes de la Corona de Castilla con una gama variopinta de plurales procedencias: vascos, extremeños, andaluces, leoneses, castellanos viejos, manchegos, murcianos y gallegos.

También es notable la variedad originaria de las gentes que se asientan en Valencia-capital o en lugares de su contribución desde los otros reinos peninsulares y del insular de Mallorca.

Tan plural procedencia subraya otra dimensión de la ciudad de Valencia: su condición de ciudad abierta a todos e incardinada sin mengua de su total valencianidad en el contexto hispano, del que el reino de Valencia ha sido y es parte solidaria, sustancial y relevante ${ }^{39}$.

\section{Inmigración extrapeninsular}

Gentes extrapeninsulares figuran en la corriente inmigratoria con un porcentaje del 4,61 por 100 y según las siguientes procedencias:

- 40,00 por 100 de italianos (lombardos, toscanos, pisanos, napolitanos, sicilianos).

33 De los inmigrantes peninsulares el 69,43 por 100 son de lengua castellana, el 25,47 de lengua catalana y el 5,10 de lengua portuguesa.

Los castellanos proceden de 44 lugares, en especial de Sevilla, Toledo y Cuenca. Los aragoneses de 31 localidades, en especial de Zaragoza y Teruel. En Cataluña los principales polos de procedencia son Barcelona y Lérida, pero llegan además de otros 16 lugares. Del reino de Mallorca proceden uno de Ibiza y otro de Menorca y los otros de la isla de Mallorca. Los portugueses proceden de Lisboa (4) $\sin$ que se precise el lugar de procedencia de los restantes (7). Llibrer de A vehinament, pub, por PILES. 
- 36,67 por 100 de franceses (roselloneses, provenzales, borgoñones, normandos, picardos).

- 15,00 por 100 de flamencos (Gante, Brujas, Bruselas, Lieja).

- 06,67 por 100 de alemanes (Colonia, Nuremberg).

- 01,66 por 100 del Magreb (Fez).

Clasificación expresiva porque los lugares de procedencia figuraban y figuran a la vanguardia de la promoción económica en los sectores secundario y terciario, por lo que no es aventurado pensar en la potencial incidencia de tales inmigrantes en ambos sectores, que alcanzan desarrollo en la Valencia del siglo XV.

El asentamiento de inmigrantes extrapeninsulares patentiza otra dimensión de la comunidad urbana valenciana: el cosmopolitismo inserto en el tejido social del reino. Dimensión importante, esencial para penetrar en la comprensión y valoración de los niveles financieros y económicos que alcanza Valencia y su función en el área de los cambios crediticios y en el tráfico mercantil ${ }^{34}$.

\section{Clasificación sectorial de la inmigración}

La clasificación profesional y laboral de los inmigrantes es otra componente esencial, porque en cierto modo revela la demanda migratoria existente en la ciudad y en su área de contribución; demanda que ejerce como factor condicionante de la corriente migratoria.

En este orden temático, tan sugestivo, los porcentajes son asimismo reveladores:

- 45,84 por 100 de inmigrantes que se integran en el sector secundario.

- 29,99 por 100 de inmigrantes vinculados al sector primario.

- 24,17 por 100 de inmigrantes encuadrados en el sector terciario.

La imagen estructural que, a mi juicio, se desprende de tales porcentajes puede definirse en los términos racionalidad y equilibrio.

Racionalidad y equilibrio en el sector primario, en el que el 93,14 por 100 de los inmigrantes son labradores y el restante $(6,86)$ pastores; porcen-

${ }^{34}$ En los Llibres de Avehinaments, en relación a los afos documentados, entre 1403 y 1443 constan: 24 italianos (de los cuales 11 son lombardos), 22 franceses (de los cuales 6 son del sur de Francia), 9 flamencos, 4 alemanes y un mercader de Fez. Tales emigrantes son mereaderes o de oficios calificados (tejedores, perayres, pelleteros, bayneros, estañeros. zapateros, etc.). Libres de Avehinaments, pub. por Pll.SS. 
tajes que pudieran reflejar la estructura agraria dominante en el término de la ciudad - más agrícola que ganadera - y acaso en el reino de Valencia.

Racionalidad y equilibrio en el sector terciario, en el que las profesiones liberales asumen un porcentaje notable ( 8,88 por 100$)$, con predominio de notarios y juristas, como índice de una sociedad preocupada por la temática administrativa y leguleya.

Los servicios figuran con un porcentaje del 8,19 por 100 , con mayoría de la hostelería y del personal sanitario. Y el porcentaje hegemonico, con el índice 74,08, corresponde a la mercadería (nada menos que 223 mercaderes inmigrantes).

\section{Ramas laborales urbanas}

En el sector secundario, el reparto de porcentajes entre las ramas laborales es revelador en cuanto al conocimiento estructural de la menestralía urbana, al punto que el mentado reparto pudiera constituir como una radiografia del organigrama de las ramas artesanales. Están documentadas las siguientes ramas:

a) Textiles y confecciones textiles: 26,25 por 100 (más de una cuarta parte de inmigrantes artesanos), con claro predominio del área de la fabricación ( 72,78 por 100) sobre el área de la confección (27,22 por $100)$, y hegemonía total de los peraires $(72,73$ por 100$)$ dentro del área de la fabricación.

b) Alimentación y comercio: 19,73 por 100, con predominio del área de la alimentación, en la que se acusa la fuerte incidencia de carniceros $(28,71)$, que sugiere una actividad y un consumo de carnes elevado; menor es el porcentaje de horneros y panaderos $(18,81)$, lo que contrasta con el porcentaje cualitativo de drogueros, especieros y boticarios $(9,09$ en conjunto) y con el de taberneros $(7,92)$. El área del comercio (botigueros, merceros, tenderos, draperos, revendedores) es de menos entidad relativa $(24,75$ por 100 del total de la rama).

c) Construcción y asimilados: 13,47 por 100, con la hegemonía reveladora de los cabanyers - constructores de cabañas y barracasque representan el 85,50 por 100 .

d) Curtidos, piel y sus confecciones: 10,54 por 100 , con predominio de los pellicers, peleteros $(33,33)$ en el área de curtidos y piel; y de los zapateros $(25,92)$ en el área de manufacturas. 
e) Transportes y actividades similares: 10,54 por 100 , con predominio de tragineros $(61,11)$ y recueros $(31,48)$ y la presencia testimonial de carreteros $(1,85)$.

f) Actividades de la mar y construcción naval: 8,59 por 100, con hegemonía de marineros y pescadores $(95,45)$ y una mínima representación de calafates y maestros de hacha $(4,55)$, lo que señala uno de los puntos más débiles de la estructura sectorial.

g) Metalurgia y manufacturas metalúrgicas: 7,62 por 100 , con claro predominio de la metalurgia $(69,57)$ sobre las manufacturas $(30,43)$.

h) Cerámica y espartería: 1,18 por 100 , índice repartido maritariamente $(0,59$ por 100$)$ entre ambas ramas.

i) Actividades diversas: 4,88 por $100^{35}$.

\section{Politica de promoción migratoria}

Obraba una normativa municipalista encaminada a estimular la inmigración. Todas las ciudades europeas del cuatrocientos, sin que me conste excepción, dada la coyuntura depresiva dominante en la demografía, procuraban potenciar la inmigración instrumentando ofertas atractivas para atraer inmigrantes.

En Mallorca, por ejemplo, al inmigrante calificado por su profesión o por su oficio no sólo se le abre el avecindamiento sino que, por acuerdo individualizado del Consell General de Mallorea, se le otorga el estatuto denominado franquesa de prevere, lo que comporta su homologación a efectos fiscales y por un término de diez años con el tratamiento fiscal privilegiado que goza el colectivo eclesiástico. Durante diez años el inmigrante no pagará impuestos municipales.

El caso de Valencia, en principio, es similar. Los Furs Antichs, los otorgados por Jaime I, no sólo homologan al inmigrante con los vecinos de la ciudad sino que, cuando el inmigrante procede de lugares de señorío, por el mero hecho de su avecindamiento, se le declara franch e absolt del homenatge axi com ciutada.

Al amparo de los Furs Antichs el inmigrante procedente de áreas señoriales o feudales queda desligado de la dependencia señorial con el consiguiente acceso a la condición de plena libertad, dado que Valencia, ciudad abierta, es ámbito de libertad y la condición de

${ }^{35}$ La gama de oficios es muy variada. Por ejemplo, en la fabricación textil están registrados: apuntadores (1), «baxadors (4), flazaderos (2), perayres (1), sederos (6), tejedores (9), tejedores (1), tejedores de velos (2), carderos (1) y tintoreros (1), En la confección: calceteros (2), juboneros (1) y sastres (1). En la alimentación: botigueros (6), carniceros (1), panaderos (9), horneros (10) y taberneros (1). Libres de Avehinaments, pub. por Pres. 
vecino de Valencia es connatural a la condición de hombre libre. Ciudadano de Valencia equivale a ciudadano libre. No hay ciudadanía sin libertad. Todos los ciudadanos de Valencia, en el sentido de vecinos de Valencia, son hombres libres ${ }^{36}$.

Ello es importante dada la gran incidencia de las áreas territoriales señoriales o feudales en el reino de Valencia. El novell vehi, nuevo vecino, entra bajo el amparo de la ciudad, se beneficia de la exención de pagar leuda y del libre aprovechamiento de los pastos comunales, y asume la obligación de pechar con los impuestos municipales como los otros vecinos.

En Valencia, por tanto, no se otorga franquicia de impuestos por diez años a los inmigrantes como se practicaba en Mallorca, por lo menos desde el siglo XV.

\section{Política de control migratorio}

La normativa migratoria, sin incurrir en contrafuero, evoluciona en sentido restrictivo en Valencia.

A partir de 1403 se intitucionaliza el vehedor dels novells vehins, inspector encargado del seguimiento, de la vigilancia, de los nuevos avecindados para comprobar si cumplen las obligaciones contraidas en el pacto de avecindamiento y, en su caso, denunciarles a la autoridad municipal competente, que podrá disponer su baja en el registro de vecinos de Valencia. Al tiempo, el nuevo vecino tiene que presentar fiadores que, en el supuesto de incumplimiento, respondan por él subsidiariamente y, en su caso, pecuniariamente, de las obligaciones dimanantes del pacto de avecindamiento.

En el decurso del siglo XV la normativa tiende a endurecerse. Los nuevos vecinos no podrán asumir funciones municipales o el ejercicio público de actividades relacionadas con la administración de la justicia hasta transcurridos ciertos años de su avecindamiento.

Es una filosofia que de hecho contempla el avecindamiento como privilegio a otorgar no al que lo solicite, sino al que además de solicitarlo merezca ser vecino de Valencia a la luz de la información preceptiva que se abre en cada caso ${ }^{37}$.

${ }^{36}$ Home strany qui no sera del regne de Valencia si vendra a la dita ciutat e al regne per raho que y sea, jatsia que y sia hom daltra sia franch e absolt de hamenatge axi com ciurada de la ciutat. dementre empero que desampar la honor perque fo hom daitra (Furs de Valencia, ed. Palmart, p.189).

37 Aparte de la información previa que se abre sobre las condiciones del que solicita el avecindamiento como novell vehi, los jurados nombran un vehedor per ensercar si los novells vehins serven go que deven servar en lurs obligacions de veynatge (si tenen lurs families e domicilis en la ciutat e contribució de quella o no). Caso do incumplimiento deben revocarles 
¿Cuántos años de antigüedad como vecino se necesitan para ejercer una función municipal? En 1494, para ser elegido consejero del Consell General, se requería una antiguiedad como vecino de por lo menos 20 años. En 1494 componían el Consell General de Valencia 136 consejeros de renovación anual $^{38}$.

En conclusión, al amparo de la normativa valenciana sobre inmigración del siglo XV será nuevo vecino de Valencia el que pruebe merecerlo - por las circunstancias que reune entendidas adecuadas - al amparo de una concepción selectiva de la inmigración de naturaleza casi elitista, tendente a promover el asentamiento de mano de obra calificada ${ }^{39}$.

Quizá ello contribuya a explicar el descenso cuantitativo de los avecindamientos respecto a los constatados en la última década del siglo XIV y también a las connotaciones de racionalidad que se observan en cuanto a la clasificación profesional o laboral de los inmigrantes.

y retirarles la carta de veynatge (jorgen ayfals vehins a tornar la carta de franquea e aquella rompen e tollen); al margen de ello los jurados, en su caso, deben promover ante el justicia civil las demandas que procedieren (los jurats insten vigorosamente [...] al justicia civil que les penes promeses per los dits vehins en lo rebiment de aquells sien exigides dells e de llurs bens).

El vehedor jura en poder del justicia y de los jurados comportarse en su oficio fealment y el notario de la universitat entregará al vehedor translat dels noms dels vehints novellament rebuts $[. .$. . e dels noms dels lochs don seran seran naturals e del nom de la parroquia, carrer. parti o loch de la ciutat a de la contribució on staran.

Los jurados, por su parte, al acceder anualmente al cargo. jurarán aplicar la normativa sobre nuevos vecinos y que no tolerarán fraudes en materia inmigratoria. Los inmigrantes tenían plazo de siete afios para trasladar a Valencia la major part de lurs bens mobles que no sien mercaderies (Furs de Valencia, ed. Palmart, p. 435-436).

${ }^{38}$ Los vecinos de Valencia que mudaran su domicilio y estuvieren ausentes de Valencia tres meses serian considerados vehins de frau, fraudulentos, y perderían la condición de vecinos de Valencia (Llibres de Avehinaments. PLES, p. 14).

${ }^{39}$ Fonch revocat e remogut (com a conseller) en Luys Olivares, barber, com no hagues vint anys fos en la present ciutat e fonch mes en loch de aquell en Pere Vich, barber, de la parroquia de Sant Salvador (AMV, Manuals de consells, sesión de 9 de agosto de 1494, A-48, f. 75 r.). 